\title{
Supply Chain Network with Remanufacturing of Used Products with Collection/Disassembly and Disposal Units
}

\author{
Siva Prasad Darla \\ School of Mechanical Engineering, Vellore Institute of Technology \\ Vellore-632014, Tamil Nadu, India \\ sivaprasaddarla@vit.ac.in
}

\begin{abstract}
In recent years, remanufacturing, recycling and disposal of product after its end of life has been increasing attention of companies not only due to environmental regulations but it is great profitable in terms of cost. In this paper, a mathematical model was developed considering production of the products with remanufacturing facility for used products, collection/disassembly and disposal facility units for recovery of used products from the customer domain. The manufacturer serves a stationary demand by producing new items of product as well as by remanufacturing the collected used items of product or disposes them after analysis of used products at collection/disassembly units. The return rate of used item is formulated as a demand like function of purchasing price and accepted quality level of used products. In this work, particle swarm optimization is proposed to solve the model and validated with a cased study. The numerical results showed that a mixed strategy of pure production and remanufacturing is optimal with scope of environment regulations.
\end{abstract}

Keyword - Used products, Remanufacturing, Disposal, Particle swarm optimization

\section{INTRODUCTION}

Rapid industrialization causes pollution and global warming which have adverse effects on the environment and this creates a need to utilize the resources to the fullest in a proper manner. The activities of the firm should not be hazardous to others. That is the firm to be eco-friendly and to meet all the norms which are laid down by the government. One of the best ways to meet the above specified requirements is that the firm should utilize the used products returned by the customers. This method in fact reduces the cost of manufacturing while being eco-friendly. The basic idea behind this paper is to develop an inventory and distribution model in supply chain network considering used products with their return ratio for remanufacturing or disposal. The work related to considering environmental criteria in supply chain decision process as a case study in [1] and the relationship between environmental uncertainty and flexibility in supply chain with performance in a manufacturing company [2] are indicating the importance of used/returned products in the supply chain.

A study is carried on generic stochastic model for the design of networks comprising both supply and return channels, which was organized in a closed loop system [3]. Single echelon forward network combined with two echelon reverse network is considered in the study. A work on assessing performance and uncertainty in developing carpet reverse logistics systems is presented in [4]. The reverse supply chain considering design and environmental factors is simulated in the work. Various network design parameters are analysed for better recycling technologies and optimizing growth and possible management options.A work on production planning of a hybrid manufacturing-remanufacturing system under uncertainty within a closed-loop supply chain is presented in [5]. The work dealt with production planning and control of a single product involving manufacturing and remanufacturing operations within a closed loop reverse logistic network with machines subject to random failures and repairs. A work on the generic model of reverse logistics network design considering both repairing and remanufacturing options is presented in [6]. Branch and bound technique applied for developed mixed integer formulation in the work. The similar work is carried out, but stochastic environment is considered [7].

Fuzzy optimization method is proposed to the inventory control and production planning problem of reverse logistics with remanufacturing and disposal recovery routes [8]. An information and communication management model is proposed for electronic components in supply chain with the option of the dispose of electronic waste and developed a WEB portal for the application purpose. Managerial implications of economic value and regulation of closed loop supply chain with correlated demands and returns are presented in [9]. The study on the single product production and inventory system with remanufacturing/reuse of return products and focusing on the rate of return products as a demand function of purchasing price and quality level is presented in [10].The deterministic and stochastic models for two-echelon suppy chain with demands and returns of products under cost structures are developed and numerical analysis carried out in [11]. 
In this paper, the basic concept is to consider returned products in a supply chain. And these returned products are considered for remanufacturing by the industry depending on purchasing price and quality factor. Once the product is found unfit for remanufacturing, it is disposed. The company takes sole responsibility of disposal of the products at its own disposal location, making sure that the pollution caused is harmless to any form of life.

Description of the problem is presented in section 3. In section 4, a mathematical formulation of the problem is presented. In section 5, the developed model is solved using proposed particle swarm optimization. The results of numerical experimentation and concluding remarks are given in section 5 and 6 respectively.

\section{Problem Formulation}

Now a day's land is not being utilized properly. Industries are disposing the products without considering whether the products can be used in remanufacturing or not. In order to reduce the pollution and utilize the resources to the fullest, in this work demand and return ratio to represent the main effecting parameters considered. The basic motto is to minimize total cost involved. This problem basically considers a single product and one period. The locations of different units involved are known. Demand for the product is considered to be stationary and the shortage is neglected. The main objective of the work is to minimize cost and improve profit with least possible pollution of optimal facility locations of disassemble/collection and disposal units.

\section{A. Supply Chain Network}

The supply chain network is developed considering suppliers, manufacturing units, distributors, customers and analysis centres. The network developed will help in deciding whether remanufacturing is apt or disposal is apt, depending on remanufacturing cost. Purchasing price and quality of the returned products are deciding factors whether the product should be considered for remanufacturing or not. Once the product is found unfit for remanufacturing, it will be disposed. The firm takes required measures while disposing. The firm takes the sole responsibility of the disposal and will avoid the environmental pollution to the maximum possible level.

This network basically consists of suppliers, manufacturing units, distributors, customers, collection/disassembly and disposal units as shown in Fig.1. The products are returned by the customers to the analysis centres which are analyse the returned products whether they are apt for remanufacturing or not, once they found them apt for remanufacturing they are sent to the manufacturing facility for remanufacturing. If returned products are found unfit for remanufacturing they are disposed.

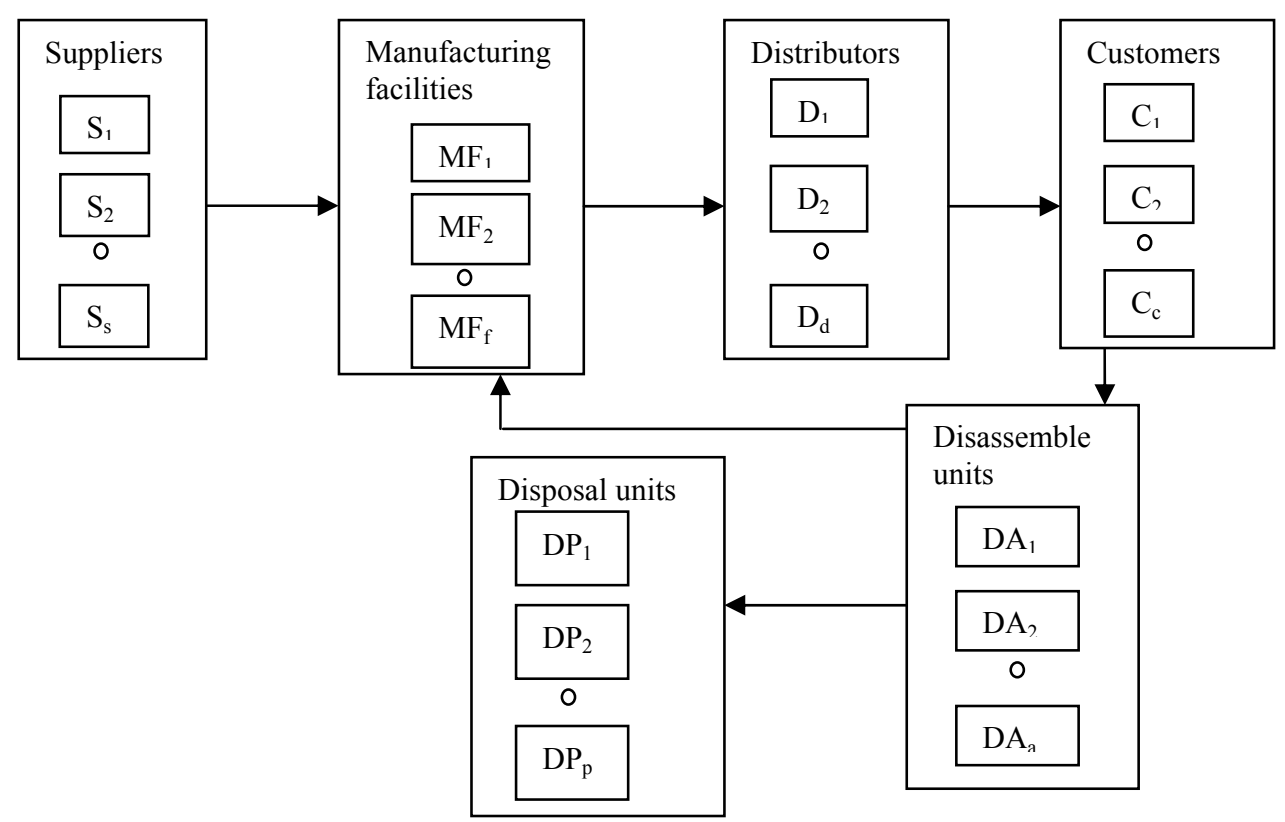

Fig.1 Supply Chain Network with disassemble and disposal units

\section{B. Mathematical Model}

In this work, the mathematical model is developed with following notations, parameters and decision variables.

Potential number of suppliers is indexed by $s$

Potential number of facilities is indexed by $\mathrm{f}$

Potential number of distributors is indexed by $\mathrm{d}$ 
Potential number of customers is indexed by c

Potential number of disassembly locations is indexed by a

Potential number of disposal locations is indexed by $p$

D- demand

$\mathrm{P}_{\mathrm{c}}$ - unit cost

$F_{i}$ - fixed cost of opening location $i$

$\mathrm{DS}_{\mathrm{ij}}$ - distance between any two locations $\mathrm{i}$ and $\mathrm{j}=\left\{\left(\mathrm{x}_{\mathrm{i}}-\mathrm{x}_{\mathrm{j}}\right)^{2}-\left(\mathrm{y}_{\mathrm{i}}-\mathrm{y}_{\mathrm{j}}\right)^{2}\right\}^{1 / 2}$, where $\left(\mathrm{x}_{\mathrm{i}}, \mathrm{y}_{\mathrm{i}}\right)$ represent the

Cartesian coordinate of location i

$\mathrm{SC}_{\mathrm{s}}$ - capacity of supplier $\mathrm{s}$

$\mathrm{FC}_{\mathrm{f}}$ - manufacturing capacity in hours of facility $\mathrm{f}$

$\mathrm{RFC}_{\mathrm{f}}$ - remanufacturing capacity in hours of facility $\mathrm{f}$

$\mathrm{DC}_{\mathrm{d}}$ - maximum capacity of distributor $\mathrm{d}$

$\mathrm{AC}_{\mathrm{a}}$ - capacity of disassembly a

$\mathrm{PC}_{\mathrm{p}}$ - capacity of disposal $\mathrm{p}$

$\mathrm{M}_{\mathrm{c}}-$ material cost per unit supplied by supplier $\mathrm{s}$

$\mathrm{c}_{\mathrm{f}}$ - manufacturing cost per unit manufactured by facility $\mathrm{f}$

$c_{r}$ - remanufacturing cost per unit remanufactured by facility $f$

$\mathrm{c}_{\mathrm{a}}$ - analysis cost per unit at analysis centre a

$c_{p}$ - disposal cost per unit disposed by disposal location $p$

$\mathrm{RN}_{\mathrm{cf}}$ - non utilized remanufacturing cost per hour of facility $f$

$\mathrm{F}_{\mathrm{hf}}$ - manufacturing time per unit in hours at facility $\mathrm{f}$

$\mathrm{RF}_{\mathrm{hf}}$ - remanufacturing time per unit in hours at facility $\mathrm{f}$

$\mathrm{DH}_{\mathrm{d}}$ - holding cost per unit per period at distributor $\mathrm{d}$

$\mathrm{B}_{\mathrm{s}}, \mathrm{B}_{\mathrm{f}}, \mathrm{B}_{\mathrm{d}}, \mathrm{B}_{\mathrm{a}}, \mathrm{B}_{\mathrm{c}}$ : batch size from supplier $\mathrm{s}$, facility $\mathrm{f}$, distributor $\mathrm{d}$, disassembly a, and, customer $\mathrm{c}$ respectively

$\mathrm{T}_{\mathrm{c}}$ : transportation cost per unit per kilometre

RR: return ratio at the first (primary) customers

$\mathrm{R}_{\mathrm{m}}$ : remanufacturing ratio

$\mathrm{R}_{\mathrm{p}}$ : disposal ratio

$\mathrm{R}$ : number of returned products

q: percentage of returned products used for remanufacturing

$\mathrm{p}$ :the percentage of the cost of raw materials required to produce new items

$\mathrm{L}_{\mathrm{i}}=\left\{\begin{array}{cc}1 & \text { if location } \mathrm{i} \text { is open } \\ 0 & \text { otherwise }\end{array}\right.$

$\mathrm{L}_{\mathrm{ij}}=\left\{\begin{array}{cc}1 & \text { if a transportation link is established between any locations } \mathrm{i} \text { and } \mathrm{j} \\ 0 & \text { otherwise }\end{array}\right.$

$Q_{i j}$ - flow of batches from location $i$ to location $j$

$\mathrm{R}_{\mathrm{d}}$ - residual inventory of the distributor $\mathrm{d}$

1) Objective function: The total cost is sum of the various costs in the supply chain network which is explained.

Total cost $=$ fixed cost + material cost + manufacturing cost + remanufacturing cost + disposal cost + transportation cost + inventory holding cost

Fixed costs $=\sum \mathrm{F}_{\mathrm{s}} \cdot \mathrm{L}_{\mathrm{s}}+\sum \mathrm{F}_{\mathrm{f}} \cdot \mathrm{F}_{\mathrm{f}}+\sum \mathrm{F}_{\mathrm{d}} \cdot \mathrm{L}_{\mathrm{d}}+\sum \mathrm{F}_{\mathrm{a}} \cdot \mathrm{L}_{\mathrm{a}}+\sum \mathrm{F}_{\mathrm{p}} \cdot \mathrm{L}_{\mathrm{p}}$

Material cost $=\sum \mathrm{Q}_{\mathrm{sf}} \cdot \mathrm{B}_{\mathrm{s}} \cdot \mathrm{M}_{\mathrm{c}}=(\mathrm{D}-\mathrm{q} \cdot \mathrm{R}) \mathrm{M}_{\mathrm{c}}$

Manufacturing cost $=\sum \sum \mathrm{Q}_{\mathrm{fd}} \cdot \mathrm{B}_{\mathrm{f}} \cdot \mathrm{c}_{\mathrm{f}}=(\mathrm{D}-\mathrm{q} \cdot \mathrm{R}) \mathrm{c}_{\mathrm{f}}$

Purchasing cost $=\sum \sum \mathrm{Q}_{\mathrm{ca}} \cdot \mathrm{B}_{\mathrm{c}} \cdot \mathrm{P}_{\mathrm{c}}=\mathrm{R} \cdot \mathrm{p} \cdot \mathrm{M}_{\mathrm{c}}$ 


$$
\begin{aligned}
& \text { Analysis cost }=\sum \sum \mathrm{Q}_{\mathrm{ca}} \cdot \mathrm{B}_{\mathrm{c}} \cdot \mathrm{c}_{\mathrm{a}}=\mathrm{R} \cdot \mathrm{c}_{\mathrm{a}} \\
& \text { Remanufacturing cost }=\sum \sum \mathrm{Q}_{\mathrm{af}} \cdot \mathrm{B}_{\mathrm{a}} \cdot \mathrm{c}_{\mathrm{r}}=\mathrm{q} \cdot \mathrm{R} \cdot \mathrm{c}_{\mathrm{r}} \\
& \text { Disposal cost }=\sum \sum \mathrm{Q}_{\mathrm{ap}} \cdot \mathrm{B}_{\mathrm{a}} \cdot \mathrm{c}_{\mathrm{p}}=(1-\mathrm{q}) \cdot \mathrm{R} \cdot \mathrm{c}_{\mathrm{p}} \\
& \text { Transportation cost }=\sum \sum \mathrm{Q}_{\mathrm{sf}} \cdot \mathrm{B}_{\mathrm{s}} \cdot \mathrm{T}_{\mathrm{c}} \cdot \mathrm{DS}_{\mathrm{sf}}+\sum \sum \mathrm{Q}_{\mathrm{fd}} \cdot \mathrm{B}_{\mathrm{f}} \cdot \mathrm{T}_{\mathrm{c}} \cdot \mathrm{DS}_{\mathrm{fd}}+\sum \sum \mathrm{Q}_{\mathrm{af}} \cdot \mathrm{B}_{\mathrm{a}} \cdot \mathrm{T}_{\mathrm{c}} \cdot \mathrm{DS}_{\mathrm{af}}+\sum \sum \mathrm{Q}_{\mathrm{ap}} \cdot \mathrm{B}_{\mathrm{a}} \cdot \mathrm{T}_{\mathrm{c}} \cdot \mathrm{DS}_{\mathrm{ap}} \\
& =\left((\mathrm{D}-\mathrm{q} \cdot \mathrm{R}) \mathrm{S}_{\mathrm{sf}}+\mathrm{D} \cdot \mathrm{S}_{\mathrm{fd}}+\mathrm{q} \cdot \mathrm{R} \cdot \mathrm{S}_{\mathrm{af}}+(1-\mathrm{q}) \mathrm{R} \cdot \mathrm{S}_{\mathrm{ap}}\right) \mathrm{T}_{\mathrm{c}}
\end{aligned}
$$

2) Constrains: The problem constrains are formulated as balance and capacity as given below and also explained.

Balance constraints

$$
\begin{aligned}
& \sum \mathrm{Q}_{\mathrm{sf}} \cdot \mathrm{B}_{\mathrm{s}}+\sum \mathrm{Q}_{\mathrm{af}} \cdot \mathrm{B}_{\mathrm{a}}=\sum \mathrm{Q}_{\mathrm{fd}} \cdot \mathrm{B}_{\mathrm{f}} \\
& \sum \mathrm{Q}_{\mathrm{fd}} \cdot \mathrm{B}_{\mathrm{f}}+\mathrm{R}_{\mathrm{d}(\mathrm{t}-1)}=\mathrm{R}_{\mathrm{dt}}+\sum \mathrm{Q}_{\mathrm{dc}} \cdot \mathrm{B}_{\mathrm{d}} \\
& \sum \mathrm{Q}_{\mathrm{dc}} \cdot \mathrm{B}_{\mathrm{d}} \leq \mathrm{D}_{\mathrm{c}}+\mathrm{D}_{\mathrm{c}(\mathrm{t}-1)}-\sum \mathrm{Q}_{\mathrm{dc}(\mathrm{t}-1)} \cdot \mathrm{B}_{\mathrm{d}} \\
& \sum Q_{c a} \cdot B_{c} \leq\left(\sum Q_{d c} \cdot B_{d}\right) R R \\
& \sum Q_{c a} \cdot B_{c}=\sum Q_{a f} \cdot B_{a}+\sum Q_{a p} \cdot B_{a} \\
& \sum Q_{c a} \cdot B_{c} \cdot R_{m}=\sum Q_{a f} \cdot B_{a} \\
& \sum Q_{c a} \cdot B_{c} \cdot R_{d}=\sum Q_{a p} \cdot B_{a}
\end{aligned}
$$

Capacity constraints

$$
\begin{aligned}
& \sum Q_{s f} \cdot B_{s} \leq S C_{s} \cdot L_{s} \\
& \sum Q_{f d} \cdot B_{f} \leq F_{c f} \cdot L_{f} \\
& \sum Q_{f d} \cdot B_{f}+R_{d(t-1)} \leq D_{c d} \\
& \sum Q_{a f} \cdot B_{a}+Q_{a p} \cdot B_{a} \leq A C_{a} \\
& \sum Q_{a p} \cdot B_{a} \leq P C_{p}
\end{aligned}
$$

Constraint (1) insures that flow entering each facility from suppliers and analysis centres is equal to the flow exiting to the distributors. Constraint (2) insures that the sum of the flow entering distributor from facility and residual inventory from previous period is equal to the exit flow to customers and residual inventory of the current period. Constraint (3) insures that flow entering to each customer does not exceed the sum of the existing period demand and previous accumulated back orders. Constraint (4) insures that the flow exiting from customer to analysis centres does not exceed the sum of entry to each customer. Constraint (5) insures that the flow entering analysis centres from customers is equal to sum of the flow exiting to facility for remanufacturing and to disposal unit for disposal. Constraint (6) insures that the flow exiting from analysis centres to facilities for remanufacturing is equal to the flow entering the analysis centres from customers multiplied by remanufacturing ratio. Constraint (7) insures that the flow exiting from analysis centres to disposal locations for disposal is equal to the flow entering the analysis centres from customers multiplied by disposal ratio. Constraint (8) insures that the flow exiting from supplier to facilities does not exceed the supplier capacity. Constraint (9) insures that the flow exiting from facilities to distributors does not exceed the facility capacity. Constraint (10) insures that the sum of the residual inventory at the distributor from the previous period and the flow entering at the existing period from the facilities does not exceed the distributor capacity. Constraint (11) insures that the sum of the flow exiting from analysis centres to all facilities and disposal locations does not exceed the analysis centre capacity. Constraint (12) insures that the flow entering into each disposal location from analysis centres does not exceed the disposing capacity.

\section{III.SOLUTION APPROACH}

Particle swarm optimization (PSO) is a search algorithm for the best solution by scientific simulating the behavior of bird swarms for feeding [12]. The PSO algorithm starts with initial population solutions and search for the optimal solution by the updating of generations [13]. The formulated mathematical model is solved using proposed particle swarm optimization method. The programming code is developed using MATLAB software. The following are the steps involved to solve the mathematical model using particle swarm optimization method.

Step 1: Input the initial particle position and velocity randomly.

Step 2: Initial population and corresponding costs are generated 
Step 3: Local (particle) best $\left(\mathrm{P}_{\mathrm{kd}}\right)$ and global best $\left(\mathrm{P}_{\mathrm{gd}}\right)$ are generated depending on the costs involved

Step 4: Update the local best and global best using particle new position and velocity equations

$$
\begin{aligned}
\mathrm{v}_{\mathrm{kd}}^{\text {new }}= & \mathrm{W} * \mathrm{~V}_{\mathrm{kd}}+\mathrm{c} 1 * \mathrm{rand}() *\left(\mathrm{P}_{\mathrm{kd}}-\mathrm{X}_{\mathrm{kd}}\right)+\mathrm{c} 2 * \operatorname{rand}() *\left(\mathrm{P}_{\mathrm{gd}}-\mathrm{X}_{\mathrm{kd}}\right) \\
& \mathrm{x}_{\mathrm{kd}}^{\text {new }}=\mathrm{x}_{\mathrm{kd}}+\mathrm{v}_{\mathrm{kd}} \text { new }
\end{aligned}
$$

where $\mathrm{c} 1, \mathrm{c} 2$ are the acceleration constants, $\operatorname{rand}()$ is a random number $[0,1], \mathrm{v}_{\mathrm{kd}}$ and $\mathrm{x}_{\mathrm{kd}}$ refers to the current velocity and position of particle $\mathrm{k}$ in the group $\mathrm{d}$ respectively, $\mathrm{w}$ is inertia weight, $\mathrm{P}_{\mathrm{kd}}$ is local (particle) best position in search process for particle $\mathrm{k}$ and $\mathrm{P}_{\mathrm{gd}}$ is global best position in search process for particle $\mathrm{k}$.

Step 5: This process is carried out for the given number of iterations

Step 6: Results are displayed showing the best particles with lowest cost

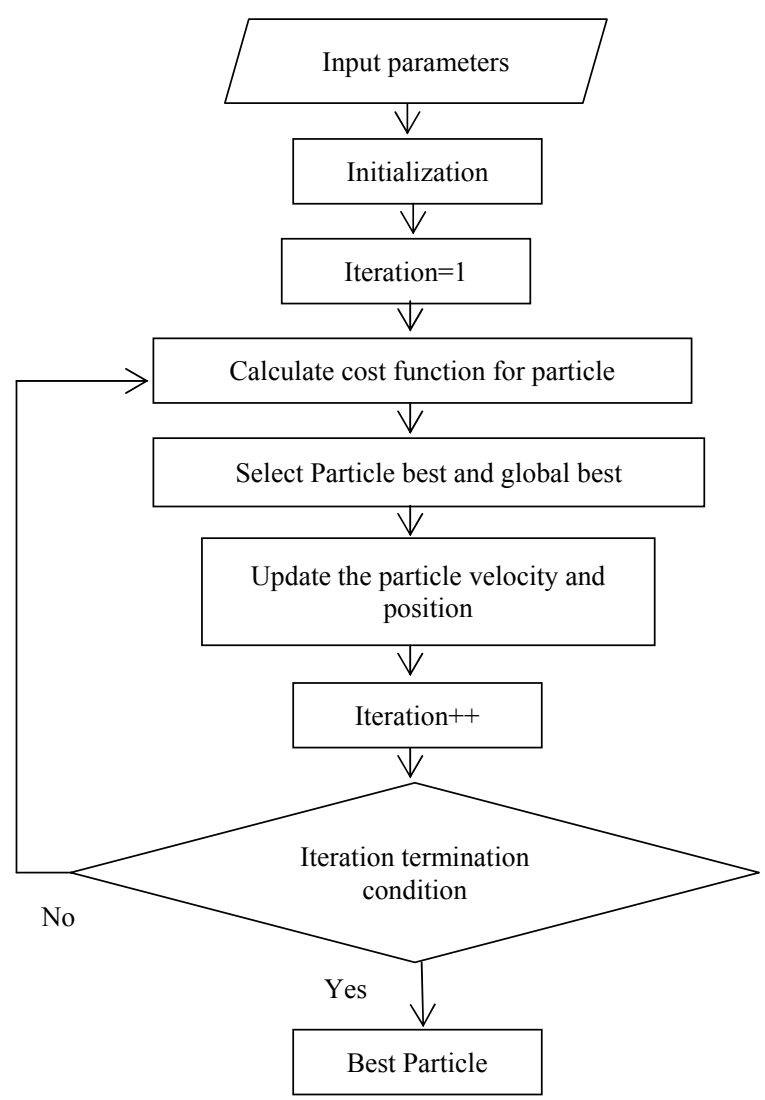

Fig.2 Flow chart for proposed algorithm

Fig. 2 shows the flow chart of solving the problem using PSO algorithm. The explanation is as follows, initially all the input parameters like costs, capacities, qualities, distances etc. are given. Initial positions and the population are generated randomly. Cost function of each particle is generated. Local best and global best are found out from the particles. Velocities of particles is calculated, new particles are generated using the formulas. These are further iterated and when the iteration reaches the given termination number, the program terminates displaying the optimal results.

\section{IV.RESULTS AND DISCUSSIONS}

The case study which is used to validate the proposed method has been taken from a small scale manufacturing company which deals with jute bags. The following data collected from thecompany: $\mathrm{D}=120000$, $\mathrm{F}_{\mathrm{s}}=150000000, \mathrm{~F}_{\mathrm{f}}=500000000, \mathrm{~F}_{\mathrm{d}}=100000000, \mathrm{~F}_{\mathrm{a}}=150000000, \mathrm{~F}_{\mathrm{p}}=100000000, \mathrm{c}_{\mathrm{r}}=24, \mathrm{c}_{\mathrm{p}}=5, \mathrm{ca}=18, \mathrm{~T}_{\mathrm{c}}=0.01$, $\mathrm{R}=36000, \mathrm{c}_{\mathrm{f}}=60, \mathrm{M}_{\mathrm{c}}=32.4, \mathrm{RR}=0.3, \mathrm{~S}_{\mathrm{sf}}=80, \mathrm{~S}_{\mathrm{fd}}=100, \mathrm{~S}_{\mathrm{af}}=2, \mathrm{~S}_{\mathrm{ap}}=2$, seta=0.0272, seta $1=0.7898$.

Eight pairs of chromosomes i.e. eight different values of $\mathrm{p}(0.25,0.15,0.23,0.29,0.31,0.31,0.29,0.27)$ and $q(0.68,0.64,0.63,0.67,0.60,0.79,0.76,0.69)$ have been taken in order to generate the initial population. The output generated by solving the mathematical model using particle swarm optimization for the above mentioned values is as shown in table I. 
Solving the developed model using particle swarm optimization, a mixed production and remanufacturing policy has the lowest cost of Indian Rupees (INR) 10102 lakhs when compared to the cost of a pure production system which comes out to be INR 10113.04 lakhs.

TABLE I. Input and Output of Network

\begin{tabular}{|l|l|l|}
\hline \multicolumn{1}{|c|}{$\mathbf{p}$} & $\mathbf{q}$ & \multicolumn{1}{c|}{ Cost (INR) } \\
\hline 0.2791 & 0.7642 & $1.0105 * 10^{9}$ \\
\hline 0.2199 & 0.7476 & $1.0104 * 10^{9}$ \\
\hline 0.2930 & 0.7525 & $1.0105 * 10^{9}$ \\
\hline 0.3947 & 0.7861 & $1.0106 * 10^{9}$ \\
\hline 0.3124 & 0.7365 & $1.0106 * 10^{9}$ \\
\hline 0.3115 & 0.8719 & $1.0102 * 10^{9}$ \\
\hline 0.2979 & 0.8244 & $1.0103 * 10^{9}$ \\
\hline 0.2880 & 0.7696 & $1.0105 * 10^{9}$ \\
\hline
\end{tabular}

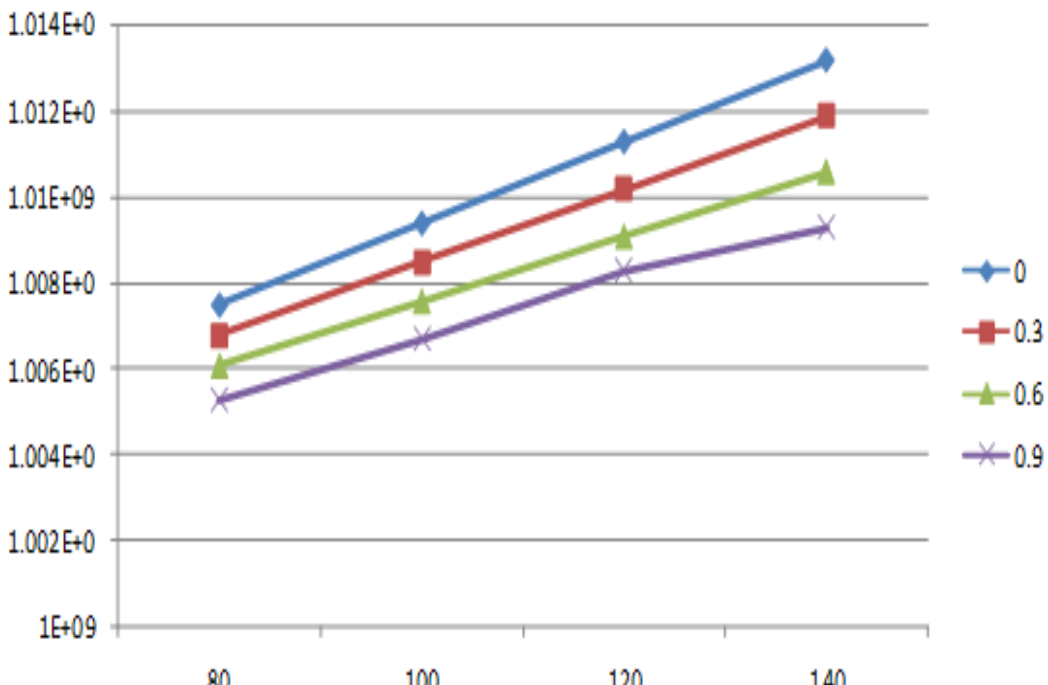

Fig. 3 Cost vs demand with return ratio

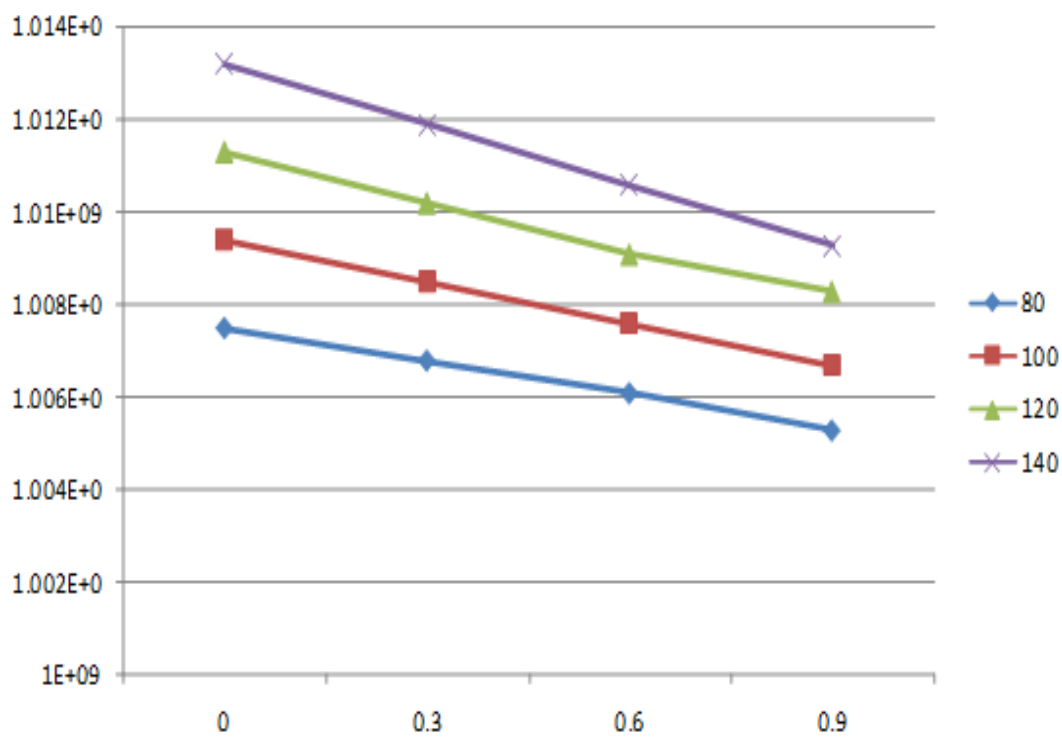

Fig. 4 Cost vs return ratio with demand 
The cost INR 10102.27 lakhs of a mixed production and remanufacturing strategy is attained when $\mathrm{p}=$ 0.3115 and $\mathrm{q}=0.8719$. A mixed strategy was found to be optimum as some of the returned items are to be remanufactured. Thus a difference of almost $0.109 \%$ was found. This reduces the cost by INR 11.04 lakhs when compared to the pure manufacturing without remanufacturing. This mixed process is eco-friendly and improves the profit. It is clear from the results that with increase in demand the cost is also increasing for varying return ratio as shown in Fig. 3. The cost is decreasing with the increase in return ratio for various demand as shown in Fig. 4. The cost is high when return ratio is 0 and is constantly decreasing with increase in return ratio for various demand of products. The results obtained from particle swarm optimization is compared with genetic algorithm for a return ratio of 0.9 (Fig.5) and for a demand rate of 140 units of product (Fig.6).

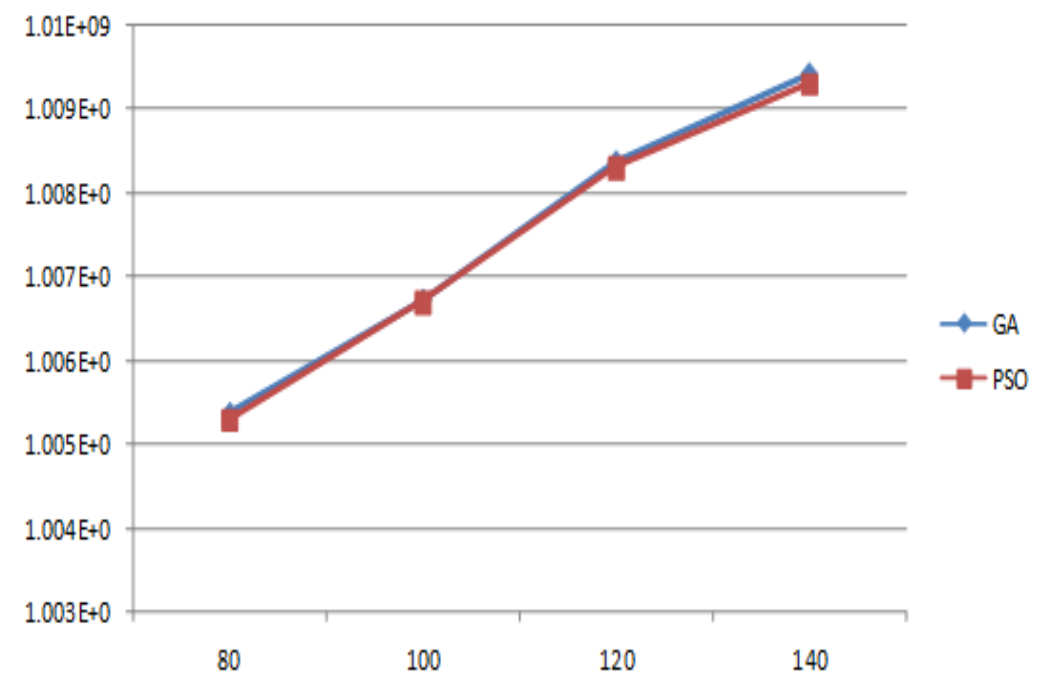

Fig. 5 Cost vs demand for PSO and GA

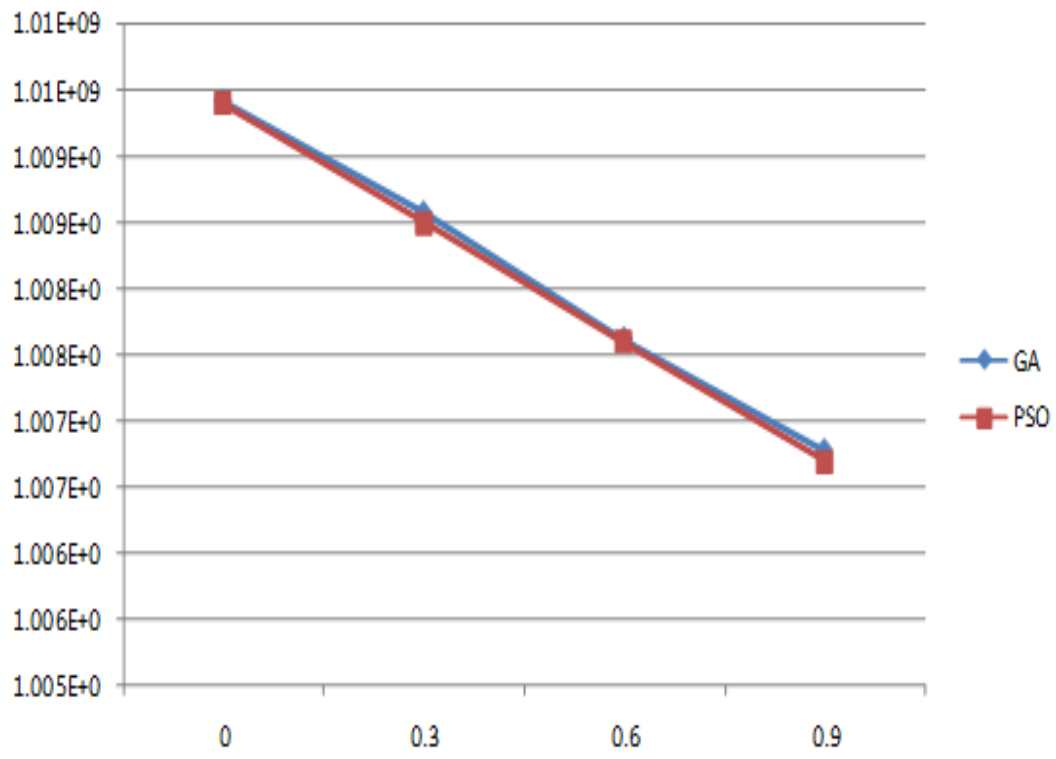

Fig. 6 Cost vs return ratio for PSO and GA 


\section{CONCLUSION}

In this paper, it is embarked with a concept of remanufacturing in regular forward supply chain and showing that manufacturing clubbed with remanufacturing concept is beneficial to both the company and environment. The developed mathematical model is solved using particle swarm optimization and compared with genetic algorithm. It is observed that the total cost of supply chain with remanufacturing of used product with collection/disassembly and disposal facilities is low in particle swarm optimization when compared to genetic algorithm. The results are discussed for varying return ratio and different demands of products. This method which was proposed is profitable at the same time it reduces pollution caused by the company, keeping it ecofriendly. This work can be extended for multiproduct and multi-period of closed loop supply chain with stochastic demand of products. A future research could be on the integrating inventory and distribution management with vehicle routing in closed loop supply chain.

\section{REFERENCES}

[1] S. Ubeda, F. J. Arcelus and J. Faulin, "Green logistics at Eroski: A case study”, Int. J. Production Ecnomics, vol. 131, pp. 44-51, 2011.

[2] M. Ulf and W. T. Ulrich, "Supply chain flexibility, uncertainty and firm performance: An empirical analysis of German manufacturing firms", Int. J.Production Ecnomics, vol. 130, pp. 43-53, 2011.

[3] A. Afia, M. El-Kharbotly and N. El-Sayed, "A stochastic model for forward-reverse logistics network desing unider risk", Computers \& Industrial Engineering, vol.58, pp. 423-431, 2010.

[4] B. Markus, P. Edmund and J. R. Matthew, "Assessing performance and uncertainty in developing carpet reverse logistics systems", Computers \& Operations Research, vol. 34, pp. 443-463, 2007.

[5] J.-P, Kenne, P. Dejax and A. Gharbi, "Production planning of a hybrid manufacturing-remanufacturing system under uncertainty within a closed-loop supply chain", Int. J. Production Economics, vol. 135, pp. 81-93, 2012.

[6] Y.-S. Zhou and S.-Y. Wang, "Generic model of reverse logistics network design", J. Transportation Systems Engineering and Information Technology, vol. 8, pp.71-78, 2008.

[7] Ovidiu Liste, "A generic stochastic model for supply-and-return network design”, Computers \& Operations Research, vol. 34, pp. 417$442,2007$.

[8] N. Petrovic, "Optimization of integrated reverse logistics networks with different product recovery routes", European Journal of Operational Research, vol. 238, pp. 143-153, 2014.

[9] R. F. Santos and F. A. S. Marins, "Integrated model for reverse logistics management of electronic products and components", Procedia Computer Science, vol. 55, pp. 575-585, 2015

[10] S. P. Darla, C. D. Naiju, K. Annamalai and Y. Upendra Sravan, "Production and remanufacturing of returned products in supply chain using modified genetic algorithm", International Journal of Industrial and Manufacturing Engineering, vol. 8, pp. 687-690, 2012.

[11] S. Mitra, "Inventory management in a two-echelon closed-loop supply chain with correlated demands and returns", Computers \& Industrial Engineering, vol. 62, pp. 870-879, 2012.

[12] Y. H. Shi and R. C. Eberhart, "Parameter selection in particle swarm optimization", in Proc. 1998 Annual Conference on Evolutionary Programming, San Diego, 1998.

[13] Kalyanmoy Deb, Optimization for Engineering Designs: Algorithms and Example,2nd ed., PHI Learning, New Delhi, 2012.

\section{AUTHOR PROFILE}

Siva Prasad Darla is an assistant professor in school of mechanical engineering at Vellore Institute of Technology, Vellore, India. His interest research areas include optimization, supply chain, product life cycle management, cost estimation and heuristic algorithms. He has several publications in international journals and conferences. 